\title{
Uses of Common Tools: Is Affordance a Base?
}

\author{
Kavita $^{1 *}$, Rajbir Singh ${ }^{2}$
}

\section{ABSTRACT}

A tool is a device that is used to achieve a task, but not consumed in the process. When in use, a tool works as a part of the user's own body not the environment. The most important point of evolution in human history was development and use of tools. The first tool was made out of stone. Thus, historians refer to the period of time before written history as Stone Age. A study is planned in which the objectives were to know the commonly available and useable tools in present day semi-urban environment, enlisting frequently used tools and their uses, categorizing the uses in terms of commonness- uniqueness and identifying the affordance in their tool. To achieve these objectives 70 samples were taken from age groups of 21-35, 36-50 and 51-65. Findings reveals 142 common human used tools, on the basis of frequency tools were divided in four categories. In these categories second and unique uses were also found. It was found that affordances enhances the efficiency of less precise, less costly, forms of social learning strategies in the acquisition of novel tool use.

Keywords: Tool use, Affordance and Uniqueness.

A tool is a device that can be used to produce an item or achieve a task, but that is not consumed in the process. When in use, a tool is a sort of extension of the hand, almost an attachment to it or a part of the user's own body, and thus is no longer a part of the environment of the user. But when not in use, the tool is simply a detached object of the environment, graspable and portable, to be sure, but nevertheless external to the observer (Gibson, 1979).

One of the most exciting issues in psychology is what are the psychological mechanisms underlying human tool use? Surprisingly, this question has received very little attention from psychologists (Johnson-Frey, 2004; Le Gall, 1992). A certain number of attempts have nevertheless been made to model how humans perform tool behavior (referred to hereafter as the HOW issue). These attempts fall into two categories. The first category assumes that tools have no inherent meaning, and thus the meaning must be created internally and stored by the user. The

\footnotetext{
${ }^{1}$ Research Scholar, Department of Psychology, MaharshiDayanand University, Rohtak

${ }^{2}$ Professor, Department of Psychology, MaharshiDayanand University, Rohtak

*Responding Author

(C) 2016 I Kavita, R Singh; licensee IJIP. This is an Open Access Research distributed under the terms of the Creative Commons Attribution License (http://creativecommons.org/licenses/by/2.0), which permits unrestricted use, distribution, and reproduction in any Medium, provided the original work is properly cited.
} 


\section{Uses of Common Tools: Is Affordance a Base?}

other category assumes that tools have inherent meanings, which is detected and exploited by the user without mental calculation.

They all are computational models, based on the core assumption that the use of a tool (e.g., a hammer) requires the extraction of sensory information about object properties (heavy, rigid), which can then be translated directly or indirectly into appropriate motor outputs (grasping, hammering). J.J. Gibson's ecological approach to perception falls into the latter category. For J. J. Gibson (1979), we do not perceive the properties of tools but what they afford (a heavy, rigid object affords pounding). This is the theory of affordances.

The concept of affordance proposed by perception psychologist, Gibson (1979) expounded that in the ecological environment animals can perceive instinctively if the objects around the environment can provide the necessities for surviving. When organisms perceive the physical properties of the environment, such as: shape and dimension, in the same time, they can perceive the functions provided by the environment as well. Gaver (1991) pointed out that the concept of affordance emphasizes human body dimensions, physical shape, the relation between properties and shape, and the perceptive information provided by objects.

An affordance is a particular kind of disposition, one whose complement is a dispositional property of the organism”. (Turvey, 1992)

The common terms in the above definition of 'affordance' are: relations, possibility, opportunity, immediacy, and interaction. So, it can be understood that affordance refers to anything that is available to the person to do something with. For example, if a person is left alone near a creek and wants to get across, a rock on the water signals to step on it and cross the creek. This affordance directly signals its relevance from an adult person on that situation but it doesn't signal for a small child who cannot see the rock (Van Lier, 2004).

There are two types of affordances: natural and cultural. The example of natural affordance is the case of flower that is relevant to bee and a flat hard surface is 'walkable-on' to the human being. The example of cultural affordance is that in the case of manufactured object or cultural artifacts, the purpose or the intended use of the object signals its purpose. In fact, the features of an object signal a kind of relevance. Cultural affordance refers to the specific meanings and values. Shotter and Newson (1982, cited in Van Lier, 2004) defines affordance in terms of all types of constraints and enablement's that are indirect and mediate.

Review of literature indicates relationship between affordance and tool uses by human. Keeping in view the thinner review of literature, present investigation was planned to check the links between uses of human tools and affordance. 
There has been rapid change in the daily life activities of the rural and urban community in India owing to the availability of abundant tools and machines. With the help of affordance a person can use one tool in a multipurpose manner. It enhances the ability to conduct work in a different and novel way.

The present investigation aims to study when, why and how does affordance guide tool use in human adults.

\section{OBJECTIVE:}

Objectives of the present study are as follows:

- To know the commonly available and useable tools in present day semi-urban environment.

- To enlisting frequently used tools and their uses.

- To categorize the uses of tools in terms of commonness/frequency of uses.

- To identify the affordance in their tool.

\section{METHODS}

\section{Sample:}

A total of $70(40+20+20)$ subjects of both gender age range from 21 to 65 were selected.

\section{Design:}

A multi-task design was employed to achieve the objectives.

Multitask procedure was used ( $\mathrm{N}-\mathrm{70})$

\begin{tabular}{|c|c|c|c|}
\hline Task-1 & Task-2 & Task-3 & Task-4 \\
\hline $\begin{array}{l}\text { T-1 Sample of } 30 \\
\text { individuals (both male } \\
\text { and female) of three } \\
\text { age groups (i.e. 21-35, } \\
36-50 \text {, and 51-65) } \\
\text { were asked to enlist } \\
\text { the name of tools they } \\
\text { are familiar. }\end{array}$ & $\begin{array}{l}\text { T-2 Same sample revisited and } \\
\text { presented with a list of } 142 \text { tools and } \\
\text { asked to arrange the tools in three } \\
\text { categories as: } \\
\text { (a) Frequently used, } \\
\text { (b) Occasionally used, and } \\
\text { (c) Do not use but they know the } \\
\text { tool }\end{array}$ & $\begin{array}{l}\text { T-3: A sample } \\
\text { of 20Ss was } \\
\text { asked to endorse } \\
\text { the tools three } \\
\text { responses: } \\
\text { common use, } \\
\text { second use and } \\
\text { the other uses. }\end{array}$ & $\begin{array}{l}\text { T-4: A sample } \\
\text { of 20Ss was } \\
\text { asked to } \\
\text { describe the } \\
\text { physical } \\
\text { properties of the } \\
\text { selected tools. }\end{array}$ \\
\hline
\end{tabular}

Purpose: Human tool uses and its affordance in daily life. To achieve purpose of the study four tasks were planned.

Task-1: prepare a list of common tools used by a person in daily routine.

Task-2: find out participants used which human tools as frequently, occasionally and how many times. This survey was conducted on same age group and participants.

Task-3: find out most frequently uses, second uses and unique uses of common human uses tools. For this purpose same age and different participants were used. This survey was conducted to find out way of dialectical novel uses on human tools.

Task-4: find out the Affordance on human used tools. For this purpose participants were given list of randomly selected tools to note down the physical properties from the list. This survey was conducted on different age and participants. 


\section{Procedure:}

Participants were contacted individually and clearly informed about the purpose of the study. After establishing the rapport with the participant, he/she was asked to understand the general instructions, however the instructions for specific human tools/task were provided separately. When the subject was comfortable and ready for the task, he/she was asked that which tools were used in commonly. They noted down the name of tools.

Task based study with each individual subject was separately done. Every effort was made to complete the job in a single sitting. How many tools were used and which tools were used in particular situation/responses also noted down. There was no time limitation for the completion of task. After completion of task participants were appreciated for their help and support.

\section{RESULTS:}

To achieve main aim of the study use of human tool and its affordance. For this purpose four surveys were conducted and results are as follows:

Primary Survey 1; results reveal that there was a list of 142 common human used tools. (List attached in appendix-I). On the basis of Survey 1, survey 2 was conducted. Results shows that 114 tools were remained on this list, on the basis of frequently used, occasionally used and unused tools but they know the tools. At the end of Survey 2, 28 tools were such as that were endorsed by subjects (listed on; Unused but they know the tool).

After Survey 2, on the basis of frequency tools were divided in four categories such as such as category 1 (frequently uses), category II (occasionally uses), category III (frequently uses + occasionally uses) and category IV (frequently uses + occasionally uses). In the end out of 114, a total of $\mathbf{3 5}$ highly frequent used tools were thus identified.

Table-1: Result of Survey 2

\begin{tabular}{|l|l|}
\hline Category of tools uses & Identified tools \\
\hline $\begin{array}{l}\text { I. Frequently used tools (frequency } \\
\text { 20) }\end{array}$ & $\begin{array}{l}\text { Total 3-tools were identified } \\
\text { Tooth-brush, Comb and Razor }\end{array}$ \\
\hline $\begin{array}{l}\text { II. Occasionally used tools (Frequency } \\
\text { 15) }\end{array}$ & $\begin{array}{l}\text { Total 3-tools were identified } \\
\text { Scissor, Knife and Blade }\end{array}$ \\
\hline $\begin{array}{l}\text { III. Frequently Occasionally } \\
\text { (Collective frequency 20) }\end{array}$ & $\begin{array}{l}\text { Total 12-tools were identified. Example: Hammer, } \\
\text { spoon, mobile, calculator, pen, nail-cutter, ball, } \\
\text { lock's key, watch, fork and remote T.V. }\end{array}$ \\
\hline $\begin{array}{l}\text { IV. Frequently Occasionally } \\
\text { (Collective frequency 15) }\end{array}$ & $\begin{array}{l}\text { Total 17-tools were identified. Example: Camera, } \\
\text { stapler, screwdriver, press, earphone, wiper, } \\
\text { matchstick, bottle, saw, basket, mug, rope etc. }\end{array}$ \\
\hline
\end{tabular}

On the basis of 35 highly frequent used tools, Survey 3 was conducted.Purpose of Survey 3: to find out the second uses and unique uses. For this purpose same sample revisited and presented with a list of 35 tools. Results revealed that the list of tools had unique and second uses present. 
Table-2: Result of Survey 3

\begin{tabular}{|l|l|l|}
\hline Tool name & Second uses & Unique uses \\
\hline Toothbrush & Hair colouring and dusting & $\begin{array}{l}\text { Transforming something liquid and dry } \\
\text { powder }\end{array}$ \\
\hline Pen & Solving untidy threads & $\begin{array}{l}\text { Marking more than one straight line with } \\
\text { ink }\end{array}$ \\
\hline Hammer & Self defense weapon & Decoration \\
\hline Blade & Putting nails on wall, self & Paperweight, decoration \\
\hline Mobile phone & Surgery, paper cutting & Rubbing written content \\
\hline Scale & Cutting vegetables & Lighting fire \\
\hline Knife & As a screwdriver & Making decorative tree of vegetables \\
\hline Razor & Cutting cloths & Cleaning woolen cloths \\
\hline
\end{tabular}

At the end the purpose of Survey 4 identified the affordance in human tool use for the purpose sample of 20 subjects were asked to describe the physical properties of the randomly selected tools.

Table-2: Result of Survey 4

\begin{tabular}{|l|l|}
\hline Tool Name & Affordance \\
\hline Toothbrush & Light, flexible, long and thin \\
\hline Comb & Spines, thin, light and easy to carry \\
\hline Pen & Pointer, long, Light and easy to handle \\
\hline Hammer & Hard, rigid, strong and heavy \\
\hline Blade & Sharp, thin, light shape \\
\hline Mobile phone & Light, smooth, fast, easy to carry and use \\
\hline Scale & Long, light, easy to carry and use \\
\hline Razor & Light weight, easy to handle and carry, sharp in use \\
\hline Screwdriver & Easy to handle and carry, rigid, light and long in shape \\
\hline Rope & Cotton and plastic made, long, light and flexible \\
\hline Clock & Three spines, plastic and iron made, various shapes \\
\hline Scissor & Spines, sharp, steel made and easy to handle \\
\hline Stapler & Shape , heavy, plastic and aluminum made \\
\hline Pen drive & Light in weight, plastic made, light shapes \\
\hline Spoon & Long, light, easy to handle and carry, etc. \\
\hline
\end{tabular}

\section{CONCLUSION:}

Keeping in view the entire findings above on the basis of all the four tasks it can be testified that various tasks were meaningful. The objective of the study was achieved. To our knowledge, the present study provides the first evidence that object affordances play a major role in the learning 


\section{Uses of Common Tools: Is Affordance a Base?}

and prediction of observed tool-use behaviors. This could arise in the absence of high-level, faithful social transmission mechanisms such as true imitation of observed action goals and means Affordances could enhance the efficiency of less precise, though less costly, forms of social learning strategies in the acquisition of novel tool use, like emulation learning or stimulus enhancement and increase ability how to work and effect of a affordance on uses of tools.

\section{REFERENCES}

Gibson, K.. (1991). Tools, Language and Intelligence: Evolutionary Implications. Man, 26(2), 255-264. http://doi.org/10.2307/2803831

Johnson-Frey, S. H. (2004). The neural bases of complex tool use in humans. Trends in Cognitive Sciences, 8, 71-78.

Le Gall, D. (1992). Apraxiesidéo-motriceetidéatoire: Revue critique de la littérature. Revue de Neuropsychologie, 2, 325-371.

Gibson, J. J. (1979). The ecological approach to visual perception. Boston: Houghton-Mifflin Co.

Gaver, W. W. (1991) Technological Affordances. Proc. CHI '91. NY: ACM, 1991.

Turvey, M. T. (1992). Affordances and prospective control: An outline of the ontology. Ecological Psychology, 4, 173-187.

Van Lier, L. (2004). The ecology and semiotics of language leaning: A sociocultural perspective. Boston: Kluwer Academic Publishers. 


\section{APPENDIX-I}

\section{List of common human used tools}

\begin{tabular}{|c|c|c|}
\hline Sr. No & Tool Name & \\
\hline 1. & Knife & Pkkdw \\
\hline 2. & Hammer & gFkkSMh \\
\hline 3. & Fork & DkVk \\
\hline 4. & Spoon & Peep \\
\hline 5. & Mobile & Qksu \\
\hline 6. & Calculator & ifjdyu ;a= \\
\hline 7. & Hand Grinder & हाथ की चक्की \\
\hline 8. & Camera & dSejk \\
\hline 9. & Pen & iSu \\
\hline 10. & Remote Controller & दरस्थू ननयोत्रक \\
\hline 11. & Stapler & क ₹: ऱगानेवाराडीयोत्र \\
\hline 12. & Screwdriver & Ikspdl \\
\hline 13. & Press (iron) & $b L+=h$ \\
\hline 14. & Shovel & QkoMk \\
\hline 15. & Vacuum Cleaner & वैक्यूमसपाई उऩकरण \\
\hline 16. & Ear Phone & कान पोन \\
\hline 17. & Lighter & राइटर \\
\hline 18. & Wiper & नोंचा \\
\hline 19. & Tooth Brush & टूथब्रश \\
\hline 20. & Comb & da?kk \\
\hline 21. & Nail Cutter & Ukk[kqu dkVus dk \\
\hline 22. & Hair Drier & Ckky $\quad$ lq[kkus dk \\
\hline 23. & Hair pin & $\begin{array}{ll}\text { Ckkyks } & \text { esa yxkus } \\
\end{array}$ \\
\hline 24. & Lock Key & PkWch \\
\hline 25. & Matches & Ekkfpl \\
\hline 26. & Ball & Xksan \\
\hline 27. & Tweezers & NksVh fpeVh \\
\hline 28. & Sewing Needle & $\mathrm{lgbZ} / \mathrm{kk} \times \mathrm{k}$ \\
\hline
\end{tabular}


Uses of Common Tools: Is Affordance a Base?

\begin{tabular}{|c|c|c|}
\hline Sr. No & Tool Name & \\
\hline 29. & Ear brush & कान ब्रश \\
\hline 30. & Locking Pliers & नचमटा तारा ऱगा \\
\hline 31. & Bar-shear & फार - कतरनी \\
\hline 32. & Clamp & dkaVk \\
\hline 33. & Loon & diMs cquus dh e"khu \\
\hline 34. & Razor & jstj \\
\hline 35. & Compass & fndlwpd \\
\hline 36. & Spade & dqnkyh \\
\hline 37. & Axe & dqYgkMh \\
\hline 38. & Gauge & Xkksyph \\
\hline 39. & Holder & gksYMj \\
\hline 40. & Paper Cutter & कागज काटनेका योत्र \\
\hline 41. & Bolt Cutter & lykl \\
\hline 42. & Chalk & $\mathrm{pkWd}$ \\
\hline 43. & Wire & Rkkj \\
\hline 44. & Rope & $\mathrm{jLIh}$ \\
\hline 45. & Tag & dkVsnkj rkj \\
\hline 46. & Oven & rUnwj \\
\hline 47. & Brush & czq"k \\
\hline 48. & Battle & cksry \\
\hline 49. & Pestle & Ekqlyh \\
\hline 50. & Stick & $\mathrm{NMh}$ \\
\hline 51. & Blade & CysM \\
\hline 52. & Clock & ?kMh \\
\hline 53. & I-Pad & आई नैैड \\
\hline 54. & Sharpener & तेजकरनेवारा \\
\hline 55. & Pencil & iSfUly \\
\hline 56. & Rubber(Eraser) & नरखावट नमटानेका रफर \\
\hline 57. & Tester & टेस्टर \\
\hline 58. & Dagger & Najk \\
\hline 59. & Cold Caini & Nsuh \\
\hline
\end{tabular}


Uses of Common Tools: Is Affordance a Base?

\begin{tabular}{|c|c|c|}
\hline Sr. No & Tool Name & \\
\hline 60. & Stone Chisel & Nsuh] Vkadh \\
\hline 62. & Balance & Rkjktw \\
\hline 63. & Bagging Hook & njkrh \\
\hline 64. & Rasp & eksVh jsrh \\
\hline 65. & Sickle & njkrh \\
\hline 66. & Oar & Ikrokj 1/4MkaMk $1 / 2$ \\
\hline 67. & Lancet & uLrj yxkus dk Najk \\
\hline 68. & Divider & Ikjdkj \\
\hline 69. & Syringe & flafjt \\
\hline 70. & Screw & fMcjh] iasp \\
\hline 71. & Spade & QkoMk \\
\hline 72. & Cleat & [kwaVk] dks;yk \\
\hline 73. & Blowpipe & Qqdauh \\
\hline 74. & Auger & Nsn djus dk cjek \\
\hline 75. & Drill & Ckjeh \\
\hline 76. & Tape & Qhrk \\
\hline 77. & Bolt & flVduh \\
\hline 78. & Funnel & dhi \\
\hline 79. & Handle & gS.My \\
\hline 80. & Roller & csyu \\
\hline 81. & Hand Saw & vkjh \\
\hline 82. & Hack Saw & Ykksgs dkVus dh vkjh \\
\hline 83. & Circular Saw & वृतीयआरा \\
\hline 84. & Jig Saw & क़तरा छोटा आरा जो मशीन सेचरता है \\
\hline 85. & Pipe-wrench & नाइऩ ररौच \\
\hline 86. & Torpedo-Level & टारऩीडो स्तर \\
\hline 87. & Needle Nose Pliers & स ईजैसीनाक वारा प्रास \\
\hline 88. & Stripper & खार उधेड़नेवारा \\
\hline 89. & Draw Hoc & $\begin{array}{l}\text { Dqnkyh } \\
\end{array}$ \\
\hline 90. & Hand draw hoe & हाथ खी:चनाक दार \\
\hline 91. & Hand Trowel & करणी \\
\hline
\end{tabular}


Uses of Common Tools: Is Affordance a Base?

\begin{tabular}{|c|c|c|}
\hline Sr. No & Tool Name & \\
\hline 92. & Trug/Basket & टोकरी \\
\hline 93. & Lamp Scissors & रैंज़सीज़सस \\
\hline 94. & Nail Scissors & नाखूनकाटनेकी कैं ची \\
\hline 95. & Button-Hole Scissors & फटन- होर कैं ची \\
\hline 96. & Tooling Plan & /kkjh jank \\
\hline 97. & Smoothing Plan & Ckkjhd jank \\
\hline 98. & Trying Plan & Ek>yk jank \\
\hline 99. & Jack Plan & jank \\
\hline 100. & Vice & laMklh \\
\hline 101. & Hand Vice & gkFkcad \\
\hline 102. & Needle Paint & fcajth \\
\hline 103. & Fishing -Rod & eNyh dkaVk \\
\hline 104. & Bellows & $\mathrm{iEi}$ \\
\hline 105. & Lever & Hkkjh rksyk n.M \\
\hline 106. & Pile & jsrh \\
\hline 107. & Anchor & Yakxj \\
\hline 108. & Hone & ekSgj \\
\hline 109. & Dibble & jaHkk \\
\hline 110. & Cone & $y V \sim V w$ \\
\hline 111. & Cleat & twrs ds Qhrs \\
\hline 112. & Spatulas & fipdkjh \\
\hline 113. & Lamp & ySEi \\
\hline 114. & Pincers & fpeVh \\
\hline 115. & Sieve & Nkyuh \\
\hline 116. & Broom & $>\mathrm{kMw}$ \\
\hline 117. & Inkpot & L;kgh nokr \\
\hline 118. & Chalk & $\mathrm{pkWd}$ \\
\hline 119. & Jar & जार \\
\hline 120. & Stove & pwYgk \\
\hline 121. & Stool & स्ट्र \\
\hline 122. & Bodkin & मोटा स आ \\
\hline
\end{tabular}


Uses of Common Tools: Is Affordance a Base?

\begin{tabular}{|l|l|l|}
\hline Sr. No & \multicolumn{1}{|c|}{ Tool Name } & \\
\hline 123. & Ruler & Ldsy \\
\hline 124. & Quill pen & ia[k okyk iSu \\
\hline 125. & Spanner & gFkdy \\
\hline 126. & Mallet & jcM okyk gFkkSMk \\
\hline 127. & Plumbine & \\
\hline 128. & Rudder & Ikrokj/4tgkt dk ia[k1/2/2 \\
\hline 129. & Trying Angle & गोननयॉr: \\
\hline 130. & Hand Cuff & gFkdMh \\
\hline 131. & Stencil & ननकृ त \\
\hline 132. & Haft- Axe & dqygkMh \\
\hline 133. & Jack Knife & tsc esa j[kus okyk pkdw \\
\hline 134. & Ladle & cMk pEpp \\
\hline 135. & Laptop & रैऩटॉऩ \\
\hline 136. & Keyboard & की फोडस \\
\hline 137. & Griddle & Rkok \\
\hline 138. & Funnel & dhi \\
\hline 139. & Tongs & fpEkVk \\
\hline 140. & Churner & e/kkuh \\
\hline 141. & Mug & MCck \\
\hline 142. & Kettle & DSryh \\
\hline 143. & Awl & स आ \\
\hline
\end{tabular}

How to cite this article: Kavita, R Singh (2016) Uses of Common Tools: Is Affordance a Base? , International journal of Indian Psychology, Volume 3, Issue 3, No. 5, DIP: 18.01.079/20160303 